\title{
F-18-FDG PET/BT'de kolanjiosellüler kanseri taklit eden Fasciola hepatica vakası
}

\section{A case of fascioliasis mimicking cholangiocellular carcinoma on (18) F-FDG PET/CT}

Hüseyin KAÇMAZ ${ }^{1}$, Elif Tuğba TUNCEL ${ }^{1}$, Berat EBİK${ }^{1}$, Feyzullah UÇMAK ${ }^{1}$, Halil KÖMEK², Muhsin KAYA Kendal YALÇIN ${ }^{1}$

Dicle Üniversitesi Tip Fakültesi Hastanesi, ${ }^{1}{ }^{1} c ̧$ Hastalkları Anabilim Dall, Gastroenteroloji Bilim Dal, Diyarbakır Gazi Yaşargil Eğitim ve Araştırma Hastanesi, ${ }^{2}$ Nükleer Tıp Kliniği, Diyarbakır

Insan fasioliazisi, Fasciola hepatica ve Fasciola gigantica'nın neden olduğu, dünya genelinde nadir görülen zoonotik bir hastalıktır. Genellikle çiftlik hayvanlarını etkileyen bir trematod olup insan rastlantısal ara konakçıdır. Spesifik olmayan semptom ve bulgularının birçok hepatobiliyer hastalıkta izlenebilmesi nedeniyle fasioliazisin tanı ve tedavisi gecikebilmektedir. Elli üç yaşında kadın hasta 18-Florodeoksi-glukoz pozitron emisyon bilgisayaralı tomo-grafi incelemesinde ekstrahepatik safra yollarında yüksek florodeoksi-glukoz tutulumu nedeniyle kliniğimize başvurdu. Hastada son 3 aydir süren karın ağrısı, kaşıntı ve halsizlik yakınmaları mevcuttu. Kolanjiyosellüler kanseri taklit eden ve serolojik olarak tanısı konan biliyer fasioliazisli bu vakayı sunacağız.

Anahtar kelimeler: Fasciola hepatica, kolanjiyosellüler kanser, F-18-FDG PET/BT
Human fascioliasis is a rare zoonotic disease caused by Fasciola hepatica and Fasciola gi-gantica. Humans may be coincidental intermediate hosts of these trematodes that usually affect livestock. Nonspecific signs and symptoms of this disease may also occur in several other hepatobiliary diseases, which potentially leads to a delay in diagnosis and treatment. A 53-year-old female patient was admitted to our clinic due to high fluorodeoxyglucose uptake in the extrahepatic bile ducts on the (18) F-fluoro-2-deoxy-D-glucose positron emission tomog-raphy scan. She had symptoms including abdominal pain, pruritus, and malaise lasting for the last 3 months. We present the case of this patient with biliary fascioliasis that mimicked chol-angiocellular carcinoma and was diagnosed serologically.

Key words: Fasciola hepatica, cholangiocellular carcinoma, (18) F-FDG PET/CT

\section{GİRIS}

Fasciola hepatica koyun, keçi ve sığır gibi çiftlik hayvanlarında yaygin olarak görülen, insanlarda sporadik olarak rastlanan, salyangozların ara konakçı olduğu bir trematoddur (1). Gelişmekte olan ülkelerde sık görülmekte olup ülkemizin bazı bölgelerinde de endemiktir (2). Hastalık akut (hepatik) ve kronik (biliyer) faz olarak tanımlanan iki fazda seyretmektedir. Karaciğer parankiminin tutulduğu akut fazda ateş, hepatomegali, karın ağrısı, anemi ve eozinofili gibi semptom ve bulgulara rastlanmaktadır. Kronik fazda ise kolestaz ve kolanjit semptom ve bulguları izlenmektedir (3). Fasioliazis tanısı klinik bulgular temelinde gaytada parazitin yumurtalarının gösterilmesi, serolojik olarak antikorun saptanması veya patolojik inceleme ile konmaktadır (4). Bahsedilen semptom ve bulgular hepatobiliyer sistemin birçok hastalığında görülen nonspesifik bulgulardır. Bu durum fasioliazis tanısının gecikmesine, uygun olmayan invaziv tanı-tedavi yöntemlerinin kullanılmasina neden olabilmektedir. Bu makalede radyolojik olarak ekstrahepatik kolanjiokarsinomu taklit eden nihai olarak fasioliazis tanısı alarak tedavi edilen vakamızı sunacağı.

\section{OLGU SUNUMU}

Elli üç yaşında kadın hasta dış merkezde yapılan 18 Florodeoksi-glukoz pozitron emisyon bilgisayaralı tomografi (F-18 FDG PET/BT) tetkikinde ekstrahepatik safra yollarında tümör ön tanısıyla kliniğimize refere edilmişti. Dış merkezdeki F-18 FDG PET/BT'de ana hepatik safra kanalından koledoka 43 mm'lik segment boyunca uzanan, en geniş yerinde 7 mm'ye ulaşan duvar kalınlaşması ve bu bölgede artmış FDG tutulumu (SUV max değeri=6.1) rapor edilmişti (Resim 1. A-D). Hastanın öyküsünde üç aydır karın ağrısı, halsizlik ve kaşıntı yakınmaları mevcuttu. Fizik muayenesi sağ üst kadran ve epigastrik bölgede hassasiyet dışında normal idi. Laboratuvar so-

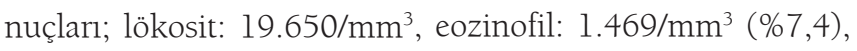
C-reaktif protein (CRP): $1,98 \mathrm{mg} / \mathrm{dl}$, alanin aminotransferaz (ALT): $452 \mathrm{IU} / \mathrm{L}$, aspartat aminotransferaz (AST): $176 \mathrm{IU} / \mathrm{L}$, alkalen fosfataz (ALP): 262 IU/L, gamma glutamil transferaz (GGT): $431 \mathrm{IU} / \mathrm{L}$, total bilirübin: $1.6 \mathrm{mg} / \mathrm{dl}$, direkt bilirübin: $1.0 \mathrm{mg} / \mathrm{dl}$ ve albümin: $3.34 \mathrm{~g} / \mathrm{dl}$ dışında normal idi. Viral ve otoimmün belirteçleri normal idi. Batın ultrasonografisinde (USG) karaciğerde grade I hepatosteatoz, koledokta lümenin tama yakın dolmasına neden olan duvar kalınlık artışı ve ko- 

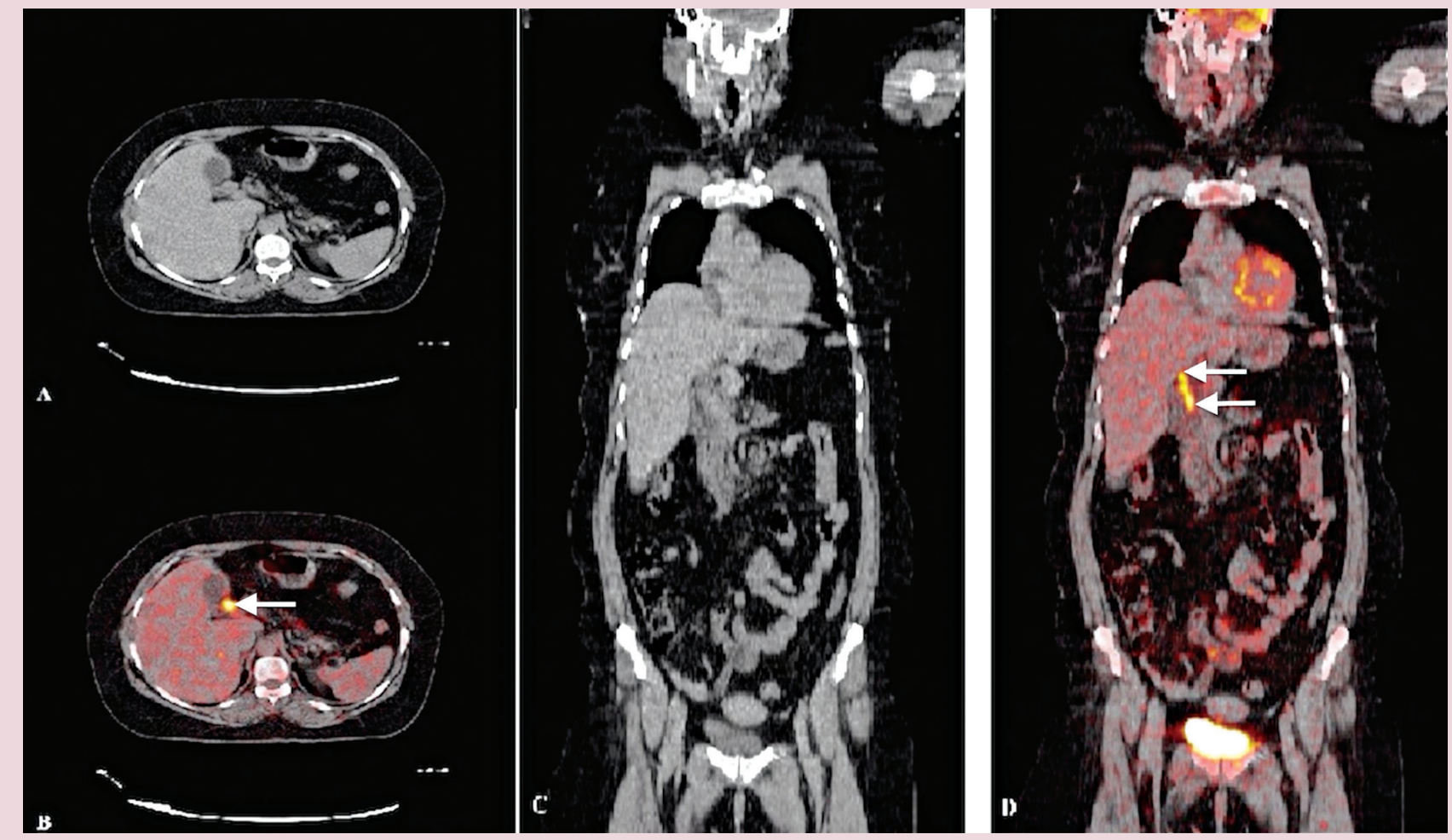

Resim 1. A-D. Hastanın aksiyal (A, B) ve koronal (C, D) F-18-FDG PET-BT görüntülerinde koledok düzeyinde duvar kalınlaşması ve malign düzeyde FDG artmış tutulumu (beyaz oklar).

ledokta dilatasyon (12 mm) rapor edildi. Kanser antijen 19.9 (CA19.9), karsinoemriyonik antijen (CEA) ve alfa-fetoprotein (AFP) dahil tümör belirteçleri normal sınılardaydı. Manyetik rezonans kolanjiopankreatikografi (MRKP) incelemesinde

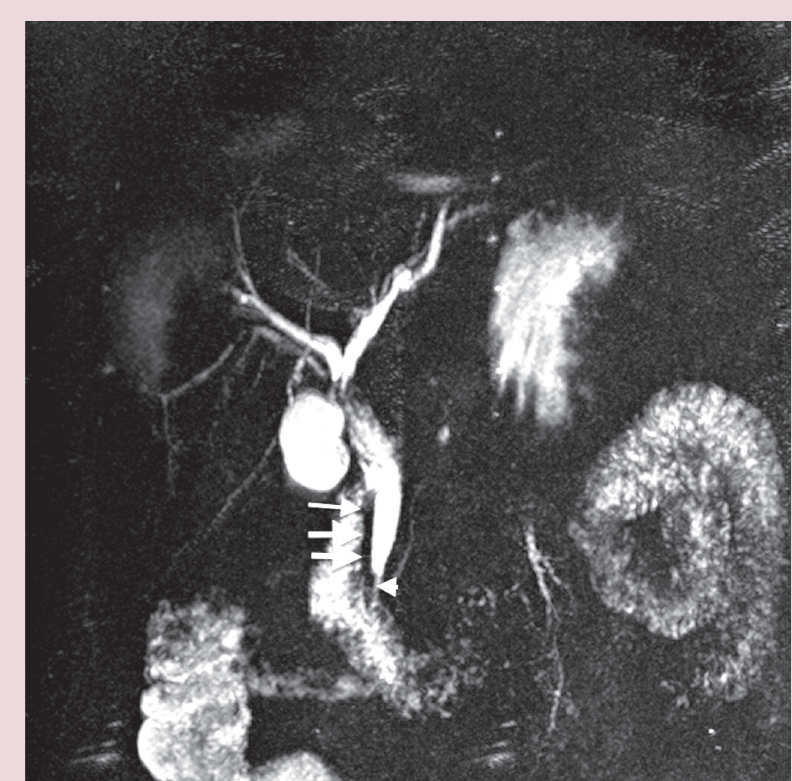

Resim 2. Hastanın MRKP görüntülemesinde koledok distalinde darlık (beyaz oklar) ve intrahepatik safra yolarında dilatasyon izlenmektedir. koledok distalinde darlık ve intrahepatik safra yolarında dilatasyon izlendi (Resim 2). Eozinofilisi nedeniyle fasioliazis ön tanısıyla istenen serumda enzim aracılıklı immünosorbent assay yöntemi ile Fasciola hepatica immünglobulin $G$ (IgG) antikoru pozitif saptand (46 DU/ml, cut off $<10 \mathrm{DU} / \mathrm{ml})$. Endoskopik retrograd kolanjiopankreatikografi (ERKP) işleminde koledok distal segmentte dolma defekti ve intrahepatik safra yollarında dilatasyon gözlendi (Resim 3A). Işlem sırasında balonla sıvazlandığında koledoktan üç adet canlı Fasciola paraziti çıkarıldı (Resim 3B). Balon işlemlerinden sonra yapilan kontrol kolanjiyogramda dolma defektinin tamamen düzeldiği görüldü. ERKP işlemini takiben hastaya $10 \mathrm{mg} / \mathrm{kg}$ dozunda tek seferlik triklabendazol tedavisi verildi. Tedavisini tamamladiktan sonraki dokuzuncu ayda kontrole gelen hasta asemptomatik olup, laboratuvar ve radyolojik bulguları tamamen normaldi.

\section{TARTIŞMA}

Fasciola hepatica enfeksiyonu endemik bölgeler dışında nadir görülür. Güney Amerika (Bolivya, Peru), Orta Doğu (M1sır ve Türkiye) ve Uzak Doğu ülkeleri dünya'da hastalığın halen endemik olarak görüldügü bölgelerdir (1). Ülkemizde Doğu Anadolu bölgesinde yapılan çalışmada seroprevalans $\% 2,78$ olarak saptanmıştır (2). Parazit, serkarya formuyla kontamine olmuş su teresinin insanlar tarafindan yenilmesi 


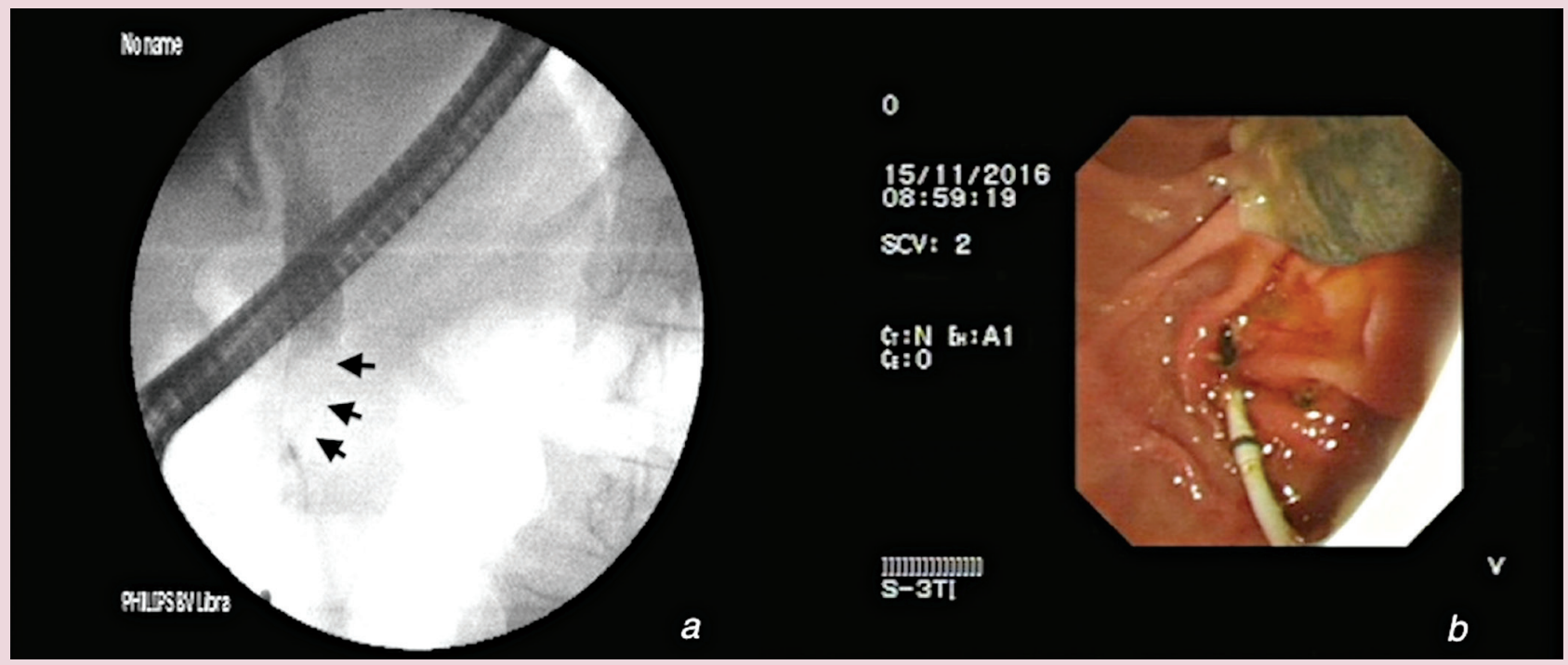

Resim 3. A, B. Hastanın ERKP görüntülemesinde (A) koledok distal segmentte dolma defekti (siyah oklar) ve balonla koledoktan duodenum lümenine çıkarılmış canlı Fasciola hepatica paraziti (B).

ile bulaşmaktadır. Bulaş sonrası ortaya çıkan larva peritoneal kaviteye geçmek için ince barsak duvarını delmektedir. Periton boşluğunda erişkin forma dönüşen larva ilerleyerek karaciğer kapsülüne ulaşır. Kapsülü geçerek hepatik parankimde ilerleyerek safra yollarına yerleşir. Safra yollarına ulaştıktan sonra parazit gelişerek 3 ay içinde erişkin formuna ulaşır $(1,5)$. Parazitin karaciğer parankim invazyon dönemini kapsayan akut hepatik ve safra yollarında yerleştiği kronik biliyer olmak üzere enfeksiyonun iki klinik fazı mevcuttur. Akut hepatik fazda ateş, sağ üst kadran ağrısı, hepatomegali gözlenir. Bu bulgular spesifik olmadığı için özellikle endemik olmayan yerlerde tanı kolaylıkla atlanabilir. Kronik biliyer fazda ise parazitin safra yollarında bulunmasına bağlı kolestaz ve kolanjit bulguları ön plana çıkmaktadır. Hastalarda en sık rastlanan laboratuvar bulgusu karaciğer fonksiyon testi (KCFT) yüksekliği olup eozinofili hastalığın başlangıç dönemlerinde saptanabilen önemli bir bulgudur (6). Bununla birlikte özellikle kronik fazda hastaların asemptomatik olabileceği akılda tutulmalıdır (7). Fasioliazis tanısı indirekt serum hemaglütinasyon, indirekt immünfloresans ve ELISA yöntemleriyle kanda antikorun gösterilmesi ya da duodenal aspirat veya gaitada Fasciola yumurtası saptanmasına dayanmaktadır (8). Biliyer fazda olan hastamızda mevcut olan kolestaz bulguları ve KCFT yüksekliği kolanjiosellüler kanser dahil diğer hepatobiliyer hastalıklarda görülebilmesine rağmen eozinofili bulgusu fasioliazis tanısını akla getirmiştir. Takiben yaptığımız serolojik incelemede yüksek titrede antikor pozitifliği saptanarak tanı konulmuştur. Hastalığın farklı evrelerinde USG, bilgisayarli tomografi (BT), manyetik rezonans görüntüleme (MRG) ve MRKP gibi radyolojik görüntüleme yöntemleri kullanılmaktadır. Genel olarak akut dönemde kontrastlı BT veya MRG, kronik fazda ise USG ve MRKP hastalığın tanısında fay- dalı olmaktadır (9). Vakamızda olduğu gibi birden fazla radyolojik görüntülemeye rağmen fasioliazis ile safra yollarının malignitesi tam olarak ayırt edilemeyebilir. Böyle durumlarda ERKP tanı ve tedavi edici yöntem olarak ön plana çıkmaktadır. Görüntüleme yöntemlerinin kombine kullanılması ve ELISA ile Fasciola hepatica antikor konfirmasyonu özellikle endemik olmayan yerlerde erken tanı için yardımcıdır (9).

F-18-FDG PET/BT gastrointestinal sistem kanserlerinde evreleme, hastalık rekkürensini saptama ve lezyonların benign-malign ayrımı gibi endikasyonlarla kullanılmaktadır. Yakın zamanda yapılmış çalışmada F-18-FDG PET/BT tetkiki safra yolları kanserlerinde tedavi planını yaparken lenf nodu metastazını belirlemede güvenilir olmasının yanısıra SUV max değerinin bağımsız prognostik faktör olduğunu göstermiştir (10). Vakamız F-18-FDG PET-BT'sinde ana hepatik safra kanalından koledoka 43 milimetrelik segment boyunca uzanan, en geniş yerinde 7 milimetreye ulaşan duvar kalınlaşması alanında malignite düzeyinde artmıs (SUV max=6,1) FDG tutulumu saptanması nedeni ile kolanjiokarsinom öntanısı ile tarafımıza refere edilmişti. Literatürde USG, BT veya MRG bulgularıyla hepatobiliyer kanserle karışan fasioliazis vakaları bildirilmiştir $(11,12)$. Bununla birlikte vakamızda olduğu gibi F-18-FDG PET/BT'de kolanjiyosellüler kanseri taklit eden fasioliazis vakasına litratürde nadiren bildirilmiş$\operatorname{tir}(13)$.

Sonuç olarak fasioliazis spesifik olmayan semptom ve bulgularla vakamızda olduğu gibi malignite dahil hepatobiliyer sistemin birçok hastalığını taklit edebilmektedir. Özellikle endemik olmayan bölgelerde serolojik yöntemler kullanılarak erken tanı sağlanması hastaların gereksiz tedavilere maruz kalmasını engelleyebilir. 


\section{KAYNAKLAR}

1. Bassily S, Iskander M, Youssef FG, et al. Sonography in diagnosis of fascioliasis. Lancet 1989;8649:1270-1.

2. Kaplan M, Kuk S, Kalkan A, et al. Fasciola hepatica seroprevalence in the Elazig region. Mikrobiyol Bul 2002;36:337-42.

3. Miman Ö, Özkeçeci T, Okur N, et al. A rare cause of obstructive jaundice: fascioliasis. Turkiye Parazitol Derg 2010;34:190-2.

4. Arjona R, Riancho JA, Aguado JM, et al. Fascioliasis in developed countries: a review of classic and aberrant forms of the disease. Medicine (Baltimore) $1995 ; 74: 13-23$.

5. Harinasuta T, Bunnag D. Liver, lung and intestinal trematodiasis In: Warren KS, Mahmoud AF, (eds.) Tropical and Geographical Diseases. New York: McGraw-Hill, 2nd ed. 1990;473-89.

6. Ezzat RF, Karboli TA., Kasnazani KA, Hamawandi AM. Endoscopic management of bili-ary fascioliasis: a case report. J Med Case Rep 2010;4:83.

7. Arslan F, Batirel A, Samasti M, et al. Fascioliasis: 3 cases with three different clinical presentations. Turk J Gastroenterol 2012;23:267-71.

8. Kodama K, Ohnishi H, Matsuo T, Matsumura T. Three cases of human fascioliasis. Kan-senshogaku Zasshi 1991;62:1620-4.
9. Dusak A, Onur MR, Cicek M, et al. Radiological imaging features of Fasciola hepatica infection - a pictorial review. J Clin Imaging Sci $2012 ; 2: 2$.

10. Ma KW, Cheung TT, She WH, et al. Diagnostic and prognostic role of 18-FDG PET/CT in the management of resectable biliary tract cancer. World J Surg 2017;Sep17. doi:10.1007/s00268-017-4192-3 (Epub ahead of print).

11. Senates E, Doğan A, Senates BE, et al. An incidental case of biliary fascioliasis mimick-ing cholangiocellular carcinoma. Infez Med 2014;22:3136.

12. Kang BK, Jung BK, Lee YS, et al. A case of Fasciola hepatica infection mimicking chol-angiocarcinoma and ITS-1 sequencing of the worm. Korean J Parasitol 2014;52:193-6.

13. Sürücü E, Demir Y, Dülger AC, et al. Fasciola Hepatica Mimicking Malignancy on 18F-Fluorodeoxyglucose-Positron Emission Tomography/ Computed Tomography. Mol Imag-ing Radionucl Ther 2016;25:143-6. 